\title{
America's Rural Hospitals: A Selective Review of 1980s Research
}

\author{
Stephen S. Mick and Laura L. Morlock
}

\begin{abstract}
We review 1980s research on American rural hospitals within the context of a decade of increasing restrictiveness in the reimbursement and operating environments. Areas addressed include rural hospital definitions, organizational and financial performance, and strategic management activities. The latter category consists of hospital closure, diversification and vertical integration, swing-bed conversion, sole community provider designation, horizontal integration and multihospital system affiliation, marketing, and patient retention. The review suggests several research needs, including: developing more meaningful definitions of rural hospitals, engaging in methodologically sound work on the effects of innovative programs and strategic management activities-including conversion of the facility itself-on rural hospital performance, and completing studies of the effects of rural hospital closure or conversion on the health of the communities served.
\end{abstract}

Any contemporary discussion of rural hospitals and their problems should include a reminder that these institutions have a long history of trials and tribulations. Stevens (1989) and Ermann (1990) have documented the resilience of rural hospitals in facing a multitude of problems in the past. Even so, the constrained health care environment of the 1980s has seemed especially troubling (American Hospital Association, 1987a; Christianson, n.d.; Ermann, 1990; Moscovice, 1989; Moscovice \& Rosenblatt, 1985a), and some (cf. Folger, 1990) predict that financial austerity will continue into the 1990s. Thus, many fear that rural-especially small, geographically isolated-hospitals may be a dying breed (cf. Berry, Shelby, Seavey, \& Tucker, 1988).

Rural hospitals differ from urban hospitals: on average they have fewer beds, older facilities, lower occupancy rates, and more reliance on Medicare reimbursement (Cleverly, 1989a; 1989b). They are often the providers of core medical services for their populations; emergency, obstetrics, and newborn services exist almost everywhere among smaller rural hospitals, in addition to conventional medical and surgical services of relatively low complexity (Hart et al., 1990; Moscovice \& Rosenblatt, 1985a). Until re-

\footnotetext{
*The research for this review was supported in part by a grant from the Agency for Health Care Policy and Research, formerly the National Center for Health Services Research and Health Care Technology Assessment, Grant No. R01-HS 05998-02. Requests for further information should be sent to: Stephen S. Mick, PhD, Department of Health Services Management and Policy, School of Public Health, University of Michigan, 1420 Washington Heights, Ann Arbor, MI 48109.
}

The Journal of Rural Health Volume 6, Number 4-October 1990 
cently, rural hospitals have been a relatively minor concern from the perspective of national health policy, perhaps because they have accounted for only 6 percent of total U.S. hospital costs (Hart, Amundson, \& Rosenblatt, 1990). Thus, until recently, public policymakers, health professionals, and academic researchers have tended to neglect this sector, despite the fact that for many areas in the United States, rural hospitals were and are the major or only provider of health services (American Hospital Association, 1988).

Understanding rural hospital trends in the 1980 s is made easier by three recent reviews that have provided details about rural hospital operations, services, financial performance, and public policy issues, among other topics (Ermann, 1990; Merlis, 1989; Moscovice, 1989). The reimbursement climate and health personnel issues affecting rural hospitals are discussed by Straub and Hicks, respectively, in this issue of The Journal of Rural Health.

An important topic that has received less discussion in these and earlier reviews is the relationship between strategic management and rural hospital performance, that is, the effects if any, of management efforts to achieve traditional and innovative goals in the face of worsening environmental circumstances. Hence, our assessment of 1980s rural hospital research focuses on what has been revealed about the capacity of these hospitals to survive, and sometimes to prosper, during a decade of tumultuous change. The following sections include a discussion of how rural hospitals may be defined, an overview of operational and financial performance indicators for rural hospitals during the 1980s, and a review of research on rural hospital productivity, costs, and major strategic management activities. A concluding section discusses significant research issues for rural hospitals during the coming decade.

\section{What Is a Rural Hospital?}

The most common definition of a rural hospital is based on geographic location outside the U.S. Census Bureau's "Metropolitan Statistical Areas" (MSAs) (see, for example, Cordes, 1989). The definition is crude, but because the Health Care Financing Administration (HCFA) uses the nonMSA/MSA distinction, and because of the need for continuity of data over time, researchers invariably return to this conventional geographic definition. In addition, as Moscovice (1989) has argued, due to the multidimensional features of the concept of "rurality" (e.g., regional and cultural differences, geographical isolation), a single, agreed-upon measure may be problematic.

An interesting example of a multidimensional approach to identifying important differences among both rural hospitals and the areas in which they are located is illustrated in the work of DeVries (1988). He developed a typology based on both the predominant economic employment of a rural community as well as the type of hospital located in that community. The 
economic base criterion contained six categories: mining/fishing/lumbering, recreation, agriculture/farming/ ranching, American Indian, manufacturing, and retirement. The hospital grouping also contained six categories: multihospital system affiliation, regional clinic/large group practice related, clinical specialty related (e.g., rehabilitation, psychiatric), comprehensive services, independent community-based, and teaching hospital networks.

DeVries (1988) argued that such a definitional scheme would improve: (1) the quality of data collection for health services research; (2) the provision of equitable practice standards and payment for care; (3) the ability of policymakers to better understand the diverse array of hospitals that serve rural America; and (4) the capacity of government, business, and other human services to work with rural hospitals. Whether these benefits would accrue remains an empirical question, but the important point is that such conceptual schemes need further development and testing. The definitional issue is critical because, first, there is still no commonly used operational definition of rural hospitals that represents an improvement over the nonMSA/MSA designation. Second, in order to understand why some rural hospitals perform better than others, the effects of environmental characteristics must be taken into consideration. In other words, rural hospitals must be classified according to relevant organizational and environmental characteristics. Until, however, there is progress on these definitional issues, we, like others, must use the non-MSA/MSA criterion.

According to this definition, in 1988 there were 2,549 rural community hospitals, a decline of 12 percent from the 1978 figure of 2,898 (American Hospital Association, 1989a). The percentages of beds represented by rural hospitals in 1978 and 1988 were 25.6 percent and 22.5 percent, respectively. In $1988,1,851(72.6 \%)$ of all rural hospitals were under 100 beds; the equivalent numbers for urban hospitals were 673 and 22.6 percent.

\section{Rural Hospital Performance: An Overview}

Numerous studies during the 1980 s concluded that many rural hospitals were in financial difficulty (cf. American Hospital Association, 1985; Moscovice \& Rosenblatt, 1985b). A 1983 study revealed that between 1973 and 1975 , 36 percent of rural hospitals (versus $23 \%$ of urban hospitals) experienced financial distress, thus supporting the view that rural hospital problems preceded Medicare's major reimbursement reform, the Prospective Payment System (PPS) (Kelly \& O'Brien, 1983). Yet, PPS's additional impact on inpatient acute care facilities has also been documented (Guterman \& Dobson, 1986). Many have argued that rural hospitals have been particularly vulnerable to financial pressures resulting from the PPS reimbursement methodology (c.f., U.S. General Accounting Office, 1990a). Why do they reason that this is the case? 
First, because the national decline in non-Medicare admissions occurred more rapidly than that for Medicare admissions, and because rural hospitals were more dependent on Medicare beneficiaries (about $40 \%$ of admissions versus $33 \%$ for urban hospitals), rural institutions became more vulnerable to financial pressures exerted by PPS. Second, although under PPS rural hospitals have been reimbursed at a lower rate than their urban counterparts, it has been argued that many of the operating costs for rural institutions are similar to or higher than those of hospitals in urban areas. For example, per unit administrative costs of compliance with regulatory programs may be higher for rural hospitals because on average they treat a smaller number of cases. Similarly, per unit supplies may be more costly due to higher shipping expenses and smaller volume purchases. In addition, rural salaries must be high to attract and retain adequately trained health personnel such as speech therapists, audiologists, respiratory therapists, and physical therapists, not to mention physicians and nurses.

Other possible factors that have been cited as contributing to rural hospital problems have included: aging facilities, often built with HillBurton funds; low profit margins relative to other hospitals while rural capital facilities were often in need of renovation; low occupancy rates and relatively wide fluctuations in census over short periods of time; vulnerability of rural hospitals to the impact of physician relocation; relatively less trained management expertise coupled with high turnover; disproportionate uncompensated care burdens; geographic isolation and inaccessibility of some rural hospitals; and the siphoning off of patients by urban hospitals through the latter's rural primary care referral centers (Fackelmann, 1986). In sum, the performance levels and financial status of rural hospitals are generally believed to be fragile. In their thorough mid-1980s assessment, Moscovice and Rosenblatt (1985b) concluded that the future was precarious and that rural hospitals needed to consider new roles and missions if they were to remain viable.

\section{Performance Indicators}

This assessment remains valid today. Table 1 displays performance indicator trend data from 1984 through 1988 that compare rural and urban hospitals generally, as well as rural and urban hospitals with fewer than 100 beds. These data were extracted from tables published by the Healthcare Financial Management Association (Cleverley, 1988, 1989a, 1989b). Their data collection process includes voluntary reporting of audited financial statements by hospitals subscribing to the Financial Analysis Service, a data analysis service of the Healthcare Financial Management Association (HFMA). Thus the sample may not be representative of all hospitals, urban or rural (Note 1). Furthermore, the panel of responding hospitals is never exactly the same year to year, which may introduce additional bias. These 
Table 1. Median Performance Indicators, All Rural and All Urban, Rural and Urban < 100 Beds, 1984 to 1988.*

\begin{tabular}{|c|c|c|c|c|c|}
\hline \multicolumn{3}{|l|}{ Indicator } & \multicolumn{3}{|l|}{ Year } \\
\hline Occupancy Percentage & 1984 & 1985 & 1986 & 1987 & 1988 \\
\hline All Rural & 55.18 & 50.54 & 50.00 & 43.77 & 45.35 \\
\hline All Urban & 69.20 & 63.61 & 61.76 & 59.92 & 59.80 \\
\hline Rural $<100$ beds & 49.53 & 44.99 & 40.68 & 42.16 & 49.52 \\
\hline Urban $<100$ beds & 59.90 & 54.49 & 47.40 & 42.16 & 49.52 \\
\hline \multicolumn{6}{|l|}{ Length of Stay } \\
\hline All Rural & 5.49 & 5.32 & 5.44 & 5.17 & 5.07 \\
\hline All Urban & 6.94 & 6.62 & 6.73 & 6.60 & 6.48 \\
\hline Rural < 100 beds & 5.03 & 4.80 & 4.78 & 4.67 & 4.58 \\
\hline Urban $<100$ beds & 5.55 & 5.22 & 5.49 & 5.36 & 5.22 \\
\hline \multicolumn{6}{|l|}{ Medicare Percentage } \\
\hline All Rural & 36.47 & 36.35 & 36.96 & 37.75 & 38.30 \\
\hline All Urban & 32.11 & 32.19 & 32.87 & 33.76 & 33.81 \\
\hline Rural $<100$ beds & 38.96 & 38.97 & 39.73 & 40.47 & 41.43 \\
\hline Rural $<100$ beds & 36.58 & 35.14 & 37.05 & 36.48 & 35.80 \\
\hline \multicolumn{6}{|c|}{ Contractual Allowance Percentage } \\
\hline All Rural & 10.23 & 10.65 & 13.43 & 15.29 & 18.16 \\
\hline All Urban & 10.95 & 10.33 & 11.40 & 14.66 & 18.55 \\
\hline Rural $<100$ beds & 8.87 & 8.73 & 11.31 & 14.32 & 16.12 \\
\hline Urban $<100$ beds & 11.55 & 7.96 & 9.31 & 12.88 & 14.72 \\
\hline \multicolumn{6}{|c|}{ Bad Debt and Charity Care Percentage } \\
\hline All Rural & 4.55 & 4.74 & 4.90 & 5.11 & 5.49 \\
\hline All Urban & 4.18 & 4.51 & 4.63 & 4.93 & 4.89 \\
\hline Rural $<100$ beds & 4.39 & 4.73 & 4.66 & 5.08 & 5.35 \\
\hline Urban $<100$ beds & 5.09 & 3.99 & 4.30 & 4.14 & 5.29 \\
\hline \multicolumn{6}{|c|}{ Outpatient Revenue Percentage } \\
\hline All Rural & 16.33 & 18.34 & 21.15 & 23.20 & 25.34 \\
\hline All Urban & 13.69 & 15.43 & 16.41 & 18.29 & 19.32 \\
\hline Rural < 100 beds & 18.38 & 19.97 & 23.13 & 24.69 & 28.06 \\
\hline Urban $<100$ beds & 18.94 & 21.15 & 24.80 & 29.92 & 28.83 \\
\hline \multicolumn{6}{|l|}{ FTEs/Occupied Bed } \\
\hline All Rural & 3.84 & 4.00 & 3.98 & 4.16 & 4.20 \\
\hline All Urban & 3.78 & 4.06 & 4.11 & 4.26 & 4.30 \\
\hline Rural $<100$ beds & 4.14 & 4.24 & 4.29 & 4.35 & 4.53 \\
\hline Urban $<100$ beds & 4.08 & 4.11 & 4.36 & 4.27 & 4.19 \\
\hline
\end{tabular}

* Data extracted from Cleverley (1989b)

caveats notwithstanding, national trend data like these are difficult to obtain, and may provide a baseline from which to begin further needed research. 
Table 1 displays several well-known trends: all hospitals experienced dramatic declines in median occupancy rates during the period 1984 to 1988. Although the rate of decline for rural hospitals equaled urban hospitals (approximately 10\% during the 5-year time period), rural hospitals were about 14 percentage points lower than urban hospitals in the base year. Among rural hospitals with fewer than 100 beds, the rate of change paralleled that of rural hospitals overall, but the initial level was about 5 percentage points below the overall rural median value as well as about 10 percentage points below smaller urban hospitals.

Median length-of-stay levels for rural hospitals were consistently shorter than those for urban hospitals. By 1988, the HFMA data show an almost 1.5day difference. Smaller rural hospitals were once again in the extreme: their lengths-of-stay were the shortest of any hospital grouping for each of the study years. By 1988, these smaller rural hospitals had about a one half day shorter length-of-stay than rural hospitals as a group.

For rural hospitals, a greater percentage of revenue came from Medicare admissions than was true for urban hospitals, a pattern observed in a number of studies (cf. Zimmerman, 1988a). Both rural and urban hospitals with less than 100 beds had higher Medicare loads than the respective all inclusive groupings. However, the smaller rural hospitals had the greatest percentage of any category: by 1988 , more than two in five patients were Medicare eligible.

Contractual allowance percentages refer to that portion of gross patient revenue that is discounted to third-party payers. The greater this value, the more pressure is placed on hospitals to find other areas in which full recovery of rates is possible. Both urban and rural hospitals had similar levels and growth rates. Smaller rural hospitals, starting initially in a better position relative to smaller urban hospitals, worsened quickly by comparison. Their 1988 percentage was, however, not as bad as rural hospitals overall.

Comparisons of bad debt and charity care indicate that rural hospitals carried a somewhat heavier load than their urban counterparts. By 1988, rural hospitals incurred 5.49 percent bad debt and charity care whereas urban hospitals incurred 4.89 percent. Over the entire period, rural hospitals delivered more of this care than did urban hospitals. During 1985-1987 smaller rural hospitals provided more of this care than did smaller urban hospitals, although by 1988 the percentages were about equal.

An important finding is that rural hospitals, in comparison to urban hospitals, obtained a greater percentage of their revenue through the provision of outpatient services. They surpassed urban hospitals by large differences during each year from 1984 through 1988. In 1988, rural hospitals obtained about 6 percent more of their revenue from this source. Smaller rural hospitals outpaced all rural hospitals. Interestingly, smaller urban hospitals led all other hospital categories in each of the 5 years for this measure, a possible reflection of smaller urban hospital attempts to find 
profitable niches in competitive urban markets.

Finally, HFMA data on full-time equivalent (FTE) personnel per occupied bed show that rural and urban hospitals had roughly equivalent levels: in 1988, for example, rural hospitals had 4.2 versus urban hospitals' $4.3 \mathrm{FTE}$ per occupied bed. Smaller rural hospitals had the highest levels on this measure in four out of the five years examined. For smaller rural hospitals, these high staffing levels, despite lower levels of occupancy, were probably a reflection of staffing requirements maintained for state licensure. Hence, the expenses of staffing were borne more heavily by these hospitals.

\section{Financial Indicators}

Table 2 displays financial indicators for 1983 to 1988 , and the generally poorer performance of rural hospitals is consistent with the findings just discussed. For example, operating and total margins show consistently lower levels for rural hospitals compared to urban hospitals. For operating margins, after an initial increase from 1983 to 1985, there was a decrease for both rural and urban hospitals. The situation for hospitals with fewer than 100 beds was worse: smaller rural hospitals experienced an overall decline into negative margins. Small urban hospitals also fared more poorly than larger ones, but not to the extent of their rural counterparts. The same patterns are evident for total margins. Increases until 1985 were followed by decreases with rural hospitals having smaller ratios than urban hospitals, and with rural hospitals with fewer than 100 beds having lower ratios than smaller urban institutions.

Measures of liquidity show a mixed picture. Data for the current ratio, the most common measure of liquidity, indicate that rural hospitals had consistently higher values than urban hospitals. The same pattern emerges for rural and urban hospitals with fewer than 100 beds: these rural hospitals had consistently higher values than the urban comparison group. In fact, in 1987 and 1988 the smaller urban hospitals were notably weaker than smaller rural hospitals.

A second measure of liquidity, days in accounts receivable, shows a general deterioration for both rural and urban hospitals. All rural hospitals declined from 62.128 days in 1983 to 72.350 days in 1988 . The trend was worse, however, for urban hospitals: from 59.988 days to 75.652 days. In 1987 , urban hospitals surpassed rural hospitals on this measure. The same pattern is evident for hospitals with fewer than 100 beds, but the deterioration of this measure for smaller urban hospitals was actually worse than for their rural counterparts.

For all rural hospitals, equity financing, a measure of capital structure, showed improvement from 1983 to 1986 then a weakening through 1988. The all-urban hospital category showed a fairly level trend, but one that was uniformly weaker than that for rural hospitals. This comparative difference 
Table 2. Median Financial Indicators, All Rural and All Urban, Rural and Urban < 100 Beds, 1983-1988.*

\begin{tabular}{|c|c|c|c|c|c|c|}
\hline \multirow{2}{*}{ Indicator } & \multicolumn{6}{|c|}{ Year } \\
\hline & & 1983 & 1984 & 1985 & 1986 & 1987 \\
\hline All Rural & 0.017 & 0.021 & 0.021 & 0.016 & 0.009 & 0.012 \\
\hline All Urban & 0.026 & 0.036 & 0.042 & 0.032 & 0.022 & 0.017 \\
\hline Rural $<100$ beds & 0.005 & 0.006 & 0.007 & 0.001 & -0.008 & -0.005 \\
\hline Urban $<100$ beds & 0.010 & 0.012 & 0.019 & 0.014 & 0.001 & 0.006 \\
\hline \multicolumn{7}{|l|}{ Total Margin } \\
\hline All Rural & 0.038 & 0.046 & 0.048 & 0.040 & 0.033 & 0.031 \\
\hline All Urban & 0.046 & 0.057 & 0.063 & 0.054 & 0.043 & NA \\
\hline Rural $<100$ beds & 0.032 & 0.032 & 0.039 & 0.030 & 0.023 & 0.021 \\
\hline Urban $<100$ beds & 0.049 & 0.033 & 0.043 & 0.042 & 0.031 & 0.024 \\
\hline \multicolumn{7}{|l|}{ Current Ratio } \\
\hline All Rural & 2.022 & 2.114 & 2.262 & 2.235 & 2.203 & 2.213 \\
\hline All Urban & 1.763 & 1.834 & 1.947 & 1.971 & 1.962 & 1.950 \\
\hline Rural $<100$ beds & 2.035 & 2.047 & 2.208 & 2.161 & 2.207 & 2.212 \\
\hline Urban $<100$ beds & 2.007 & 1.966 & 1.968 & 1.996 & 1.853 & 1.863 \\
\hline \multicolumn{7}{|c|}{ Days in Accounts Receivable } \\
\hline All Rural & 62.128 & 67.391 & 69.926 & 70.645 & 71.795 & 72.350 \\
\hline All Urban & 59.988 & 64.988 & 68.596 & 69.468 & 73.471 & 75.652 \\
\hline Rural $<100$ beds & 61.699 & 67.447 & 70.765 & 70.980 & 72.135 & 71.306 \\
\hline Urban $<100$ beds & 59.984 & 67.033 & 71.057 & 70.582 & 78.275 & 78.460 \\
\hline \multicolumn{7}{|l|}{ Equity Financing } \\
\hline All Rural & 0.528 & 0.563 & 0.594 & 0.600 & 0.585 & 0.576 \\
\hline All Urban & 0.470 & 0.543 & 0.488 & 0.488 & 0.481 & 0.472 \\
\hline Rural $<100$ beds & 0.576 & 0.631 & 0.648 & 0.649 & 0.634 & 0.640 \\
\hline Urban $<100$ beds & 0.518 & 0.479 & 0.526 & 0.504 & 0.435 & 0.392 \\
\hline \multicolumn{7}{|l|}{ Average Age of Plant } \\
\hline All Rural & 7.318 & 7.460 & 7.645 & 7.828 & 7.971 & 8.415 \\
\hline All Urban & 6.736 & 6.808 & 6.861 & 6.983 & 6.939 & 7.099 \\
\hline Rural $<100$ beds & 7.858 & 8.014 & 8.172 & 8.469 & 8.593 & 9.322 \\
\hline Urban $<100$ beds & 7.438 & 7.787 & 7.812 & 7.777 & 6.982 & 7.058 \\
\hline
\end{tabular}

* Data extracted from Cleverley $(1988 ; 1989 a)$.

was even stronger for hospitals with fewer than 100 beds. The equity financing ratio for smaller urban hospitals weakened appreciably after 1986. Finally, in every year, the ratio for smaller rural hospitals was higher than for the all-rural hospital category.

For average age of plant, a proxy for how quickly a hospital was renovating and improving its physical facilities, an aging process was 
underway with rural hospitals consistently older than urban hospitals as well as aging at a faster rate. An even more extreme aging pattern was observed for smaller rural hospitals.

What these data suggest is that, at least among reporting hospitals, the profit picture for rural hospitals was weaker than for urban hospitals and worsened over time. The liquidity picture, although it appeared to favor rural hospitals, was probably a reflection of their lower access to the debt markets in comparison to urban hospitals (Deloitte \& Touche \& Health Care Investment Analysts, Inc., 1990). High levels of current ratios for both allrural and smaller rural hospitals possibly also reflected concern about short-term obligations like payroll and fears of insolvency. Hence, for rural hospitals a combination of worried, conservative financial policy coupled with a lack of borrowing opportunity kept liquidity high, debt service relatively low, but at the expense of a rapidly aging physical infrastructure (Note 2).

Numerous state-level studies, some using measures similar to the HFMA reports, are consistent with these national-level data. For example, studies of Texas (Bailey, Boff, \& Rampmeier, 1988), Oklahoma (Oklahoma Medical Research Foundation, 1989), Kansas (Wilson \& Hungerford, 1984), and Michigan (Clark, Hamilton, \& Lester, 1989) present data indicating weak or declining performance and financial indicators for rural hospitals during this time period.

\section{Productivity and Costs}

Studies that focused on rural and urban differences in productivity and cost levels include Cromwell and Puskin (1989), who concluded that during the period 1984 to 1987, expenses per discharge grew somewhat faster in rural hospitals than in urban hospitals. This pattern was due primarily to a greater increase in the rate of growth in hours per discharge, which reflected higher growth rates in hours per intermediate serviceand inpatient services per discharge. Unfortunately, pre-PPS rates were not disaggregated by rural or urban status. However, the overall data show a slowdown of expenses per discharge in the pre- and post-PPS comparisons for hospitals with less than 50 beds, the majority of which were probably rural. Although rural hospitals appear not to have been as productive as urban hospitals, they may have been substituting more outpatient care for inpatient care than urban hospitals (Table 1), leaving a greater proportion of severe cases in the inpatient setting.

Cromwell (1989), using data for Medicare diagnosis-related groups (DRGs) in 1983-1984, also showed that rural hospitals averaged 14.2 discharges per 1,000 in the most nonlabor-intensive DRGs compared to 32.5 per 1,000 for urban hospitals. Rural hospitals averaged 19.8 discharges per 1,000 in the most labor-intensive DRGs compared to 27.2 discharges per 
1,000 for urban hospitals. Thus, Medicare discharges in rural hospitals tended to be found among a middle group of labor-intensive DRGs. Cromwell (1989) concluded that most of the rural-urban distinction in labor intensity could be explained by differences in bed size and the smaller range of services in rural hospitals with fewer than 50 beds: fewer than five discharges per 1,000 in these latter hospitals were in the 10 most laborintensive DRGs. The important policy conclusion was that although rural hospitals may have been underpaid for a few intensive procedures, such cases were rare, so that on balance rural hospitals were not underpaid.

In contrast, a study by Long, Fisher, and Dreachslin (1988) compared pediatric services in 130 non-teaching urban hospitals with 97 rural hospitals. Based on pre-PPS 1982 data, this study showed similar distributions of pediatric services according to diagnostic category, DRGs, and severity as measured by disease staging. Urban average length-of-stay was about one third of a day longer, and the urban average charge was $\$ 458$ more. Because both rural and urban hospitals treated similar pediatric patients, the authors concluded that differential payment rates favoring urban hospitals seem justified only if exogenous, uncontrolled input prices were higher.

In a study based on pooled 1982 Medicare Part A and B data for several DRGs in four states, Cromwell, Mitchell, Carlore, and Iezzoni (1987) adjusted rural-urban hospital costs by the $1984 \mathrm{HCFA}$ wage index and found that only one-third of the rural-urban differential was based on cost variation. DRG case mix was much less important, explaining only about 10 to 15 percent of the cost difference, even with the addition of various controls for severity. The presence of large urban teaching hospitals accounted for roughly two thirds of the rural-urban ancillary intensity difference, suggesting that the real rural-urban differential was a function of the aggressive, intensive medical practice styles of teaching institutions rather than of differences between rural hospitals and an undifferentiated class of "urban" hospitals.

Research on whether rural referral centers-HCFA-identified centers for special treatment under Medicare PPS-were as costly as urban hospitals showed that in 1984, although the rural referral centers' costs per case were 13 percent higher than other rural hospitals, they were 9 percent lower than urban hospitals, controlling for case mix, teaching status, and wages (Hendricks \& Cromwell, 1989).

Hogan (1988) found that despite the many differences between rural and urban hospitals, the cost per unadjusted discharge between the two types of hospitals remained constant between 1981 and 1985. In each year, the rural-urban ratio was 0.59 despite increases for both types of hospitals of about 50 percent during the four-year period. Hogan noted (1988) that inpatient revenue from Medicare grew much faster in urban hospitals than in rural ones ( $13.3 \%$ versus $21.7 \%$ ). It should be noted that this and other studies derived from the recent Hospital Cost and Utilization Project (HCUP-2) explicitly exclude hospitals with fewer than 30 beds, which 
essentially omits representation of about 200 rural hospitals (Coffey \& Farley, 1988).

In sum, this portrait of rural hospital organizational and financial performance usually, but not always, showed rural hospitals at lower levels compared to urban hospitals, as well as a general worsening over time. Some of the studies reviewed suggest that rural hospitals were in some difficulty before PPS and imply that other forces, discussed in the introductory section, have contributed to performance decline. The research on rural-urban productivity and cost differences contains disagreement on both fact and interpretation, an unfortunate circumstance in light of the current debate about the justification of the PPS payment differential, which at one point paid urban hospitals an average of 37 percent more than rural hospitals (National Rural Health Association, 1988).

Finally, with the major exception regarding differential PPS payment favoring urban hospitals, there is no inherent reason why comparisons of rural hospitals should always be made to urban hospitals, operating, as they are presumed to do, in totally different circumstances. The study of these performance measures among rural hospitals with varying characteristics should be meaningful in itself, especially in view of the critical importance many of these institutions have for health care services in their communities. That many of these performance measures continue to decline should be cause for concern.

A good example of the type of studies that are needed is the recent Government Accounting Office (GAO) analysis of differences between financially successful and distressed rural hospitals (United States General Accounting Office, 1990a). They found that the patient mix of financially distressed rural hospitals was characterized by both higher proportions of Medicare patients and uncompensated care. At 34 percent of the distressed rural hospitals-in comparison to 21 percent of financially successful rural hospitals-Medicare inpatient days accounted for more than 60 percent of all patient days in Fiscal Year 1987. The GAO (1990a) concluded, however:

"While losses on the hospitals' Medicare patients were significant for the distressed hospitals, their average losses on other patients were considerably larger. Consequently, increases in Medicare payment alone are not likely to result in profits for the most distressed hospitals" (p. 18).

\section{Strategy: Organizational and Corporate Redesign}

In view of the generally poorer performance picture that existed for rural hospitals, it is not surprising that prescriptive advice abounded during the 1980s. The Section for Small and Rural Hospitals of the American Hospital Association (AHA) suggested that hospitals try "planned organizational 
change," "strategic planning and management," "reorganization along corporate models," "diversification," "marketing," and "strategies for physician recruitment and retention" (Weiss, Phillips \& Schuman, 1986). The National Rural Health Association published instructive, detailed manuals for rural hospital strategic planning (cf. Buada, Pomeranz, \& Rosenberg, 1985), as well as for the development of specific services and interorganizational linkages.

The trade and academic literature exhorted rural hospital managers to use marketing (DeSalvo, 1986), to convert standing beds to swing beds (Newald, 1986), to develop health promotion programs (McCormick, 1986), and to upgrade management expertise (Boissoneau, 1985). Boeder (1989) asserted that rural hospitals that were successful in the 1980 s concentrated on three areas: affiliating or networking with other hospitals; opening outpatient, transitional, or long-term care services; and, engaging in aggressive recruiting and retaining of physicians. Finch and Christenson (1981) suggested that fewer total beds should be concentrated in larger, better utilized facilities to lower average costs per patient day. These and other activities, subsumed under the heading "strategic management," presume that rural hospitals should reformulate their stance relative to their environment to improve their chance of survival.

Although theory and research (in comparison to prescriptive writing) on strategic management behavior has developed widely in the general organization and management literature, an integrated focus on health care organization and management is a very recent development (Shortell \& Zajac, 1990). In the area of rural health care, a coherent theoretical approach is even rarer, although a recent paper by Smith and Piland (1990) has drawn together the pertinent writing in a systematic synthesis and a proposed research agenda. An important feature of strategic management writing in rural hospitals specifically and organizations generally is the assumption that administrators, faced with dire financial and other constraints, will respond positively, creatively, and willingly to the challenges, opportunities, and risks of change.

Another perspective, the so-called threat-rigidity hypothesis, has been almost entirely neglected in the rural hospital area (as well as in the study of health care organizations generally). It is much more pessimistic about the capacity of organizations under stress, such as financial hardship, to react positively (Staw, Sandelands, \& Dutton, 1981). Some argue that after initial threats lead to organizational decline, there follows a diminution of dysfunctional forces that restrict innovative organizational response (Sutton \& D'Aunno, 1989). Therefore, there may be some hope that the initial maladaptive behavior of rural hospital administrators might be reversed. But at first, given the litany of grievously negative forces affecting rural hospitals in the 1980s (American Hospital Association, 1987b); one could well conclude that manifestations of threat-rigidity (e.g., restrictions on information processing such as total reliance on standard operating proce- 
dures, centralization and formalization of control, and conservation of resources as exemplified in tight cost accounting) would be the norm for rural hospitals. No research has confirmed or disconfirmed this or any related hypothesis.

In addition, it should be noted that much of the hospital management literature (with the notable exception of researchers who adopt a population ecology framework) assumes that financial performance is a function of factors subject to managerial control. However, the extent to which hospital performance actually reflects managerial decisions and activities, in comparison to other factors such as geographic location, has been the subject of relatively little empirical investigation.

Thus, in the remainder of this section, we briefly review the rural hospital strategic management activities for which there is some research literature. To begin, we discuss the contribution of case study analysis to our understanding of strategy making in rural hospitals.

\section{Case Studies}

Nearing completion or currently underway are several case study projects that describe strategic management activities in rural hospitals and attempt to discern the causal connection between the factors that lead to such activities and whether the activities are effective (Ambulatory Care Professionals of the American Hospital Association, 1990; Amundson and Rosenblatt, 1988; Hospital Research and Educational Trust, 1989). These studies suggest not only wide performance variability, but also how performance is contingent upon particular environmental circumstances. One such study (Ambulatory Care Professionals of the American Hospital Association, 1990) argues that elimination of the PPS rural-urban differential would be helpful, a conclusion that contrasts with large-sample statistical studies that find some justification for the higher urban rates (cf. Bowen, 1987). These ongoing case studies, however, should help illuminate the findings that will arise from large scale statistical cost studies (cf., Cromwell, 1989; Cromwell and Puskin, 1989), strategic management studies (Mick, Morlock, Salkever, de Lissovoy, Maltiz, \& Jones, 1990), studies of rural health consortia (University of Minnesota Center for Health Services Research, 1990), and the HCFA-funded evaluation studies of the rural health care transition grants program (Ernest \& Young, 1990).

\section{Hospital Closure}

Closure, as drastic as it may be, is both a form and an outcome of strategic management activity (Ermann, 1990). It may be the reluctant decision by administrators, trustees, and providers that a facility can no longer function 
financially, or the deliberate product of a decision that a rural hospital can serve its community better in some radically altered form. Closures can be the unintended outcome of poor decisions, poor management, and hostile environmental forces, or the planned outcome of wise decisions and sagacious management. Studies of closure have been of two general types: descriptive studies, i.e., how many and what kind of hospitals have closed, and explanatory studies that analyze the factors associated with closure. Except for some speculation on the implications of closure, there has been very little assessment of the consequences of closure on the surrounding community.

A three-statestudy (Arizona, Maryland, and Pennsylvania) showed that 53 hospitals closed between 1960 and 1980 (Kennedy \& Dumas, 1983). During the same period, 68 hospitals opened, yielding a net change of +15 . Smaller size and lower occupancy levels were the only variables associated with closure. Although rural versus urban location was not considered in the analysis, each state, particularly Pennsylvania, had rural populations and hospitals, and the impression is that closure in rural areas was partially offset by new facilities. Another study of hospital closures during 1976 to 1980 found that 226 community hospitals had closed, 148 of which were located in urban areas and 78 in rural areas (Mullner, Byre, \& Kubal, 1983). The closure rate per 100 hospitals was much higher for urban hospitals (5.0 per 100$)$ than for those in rural areas $(2.7$ per 100$)$. Hence, location in a rural area had not yet emerged as a distinctive problem or an important variable in predicting closure.

In a more analytic, retrospective case-controlled study of this same 1976 to 1980 period, Longo and Chase (1984) found that among the most important predictors of hospital failure were a higher physician-to-population ratio, location in the East North Central and West North Central census regions, a lower level of diversification, size fewer than 50 beds, and location in a Standard Metropolitan Statistical Area (SMSA). Hence, rural location was actually negatively associated with closure. Another case-controlled study of rural hospitals that closed between 1970 and 1980 identified 148 closures among hospitals with fewer than 100 beds (Mayer, Kohlenberg, Sieferman, \& Rosenblatt, 1987). The factor most strongly predictive of closure was for-profit status; lower occupancy rate was also an important variable, but only for rural hospitals located in counties adjacent to metropolitan counties.

By the mid-1980s, new reports began to assess the impact on hospital closure of the turbulent events opening the decade. Mullner and McNeil (1986) counted 340 community and specialty hospital closures between 1980 and 1985: urban hospital closures once again led rural hospitals, 221 versus 119. The closure rate per 100 hospitals was also higher for urban hospitals: 5.8 per 100 versus 3.7 per 100 . However, the closings, interpreted in bed rate closures, showed rural hospitals with a slightly greater loss: 3.8 per 100 versus 3.5 per 100 . The authors hypothesized that lower levels of 
interhospital competition were probably present among rural hospitals and that may have been a reason for the lower closure rates. They also speculated that rural hospitals may have had greater community support in time of need.

In a study of hospital closures between 1980 and 1985, Gifford and Mullner (1988) developed theoretical propositions to explain hospital closure and concluded that hospitals with strong community connections and orientations were less likely to close even in the face of stringent competition and diminished resources. Another study of hospital closures revealed that shutdowns, after declining from 1980 to 1982, began to increase each year until 1987. In 1986, for the first time in any of the reported literature, rural hospital closures were higher than urban hospitals, but then equaled urban hospital closures in the following year (Mullner \& Whiteis, 1988). Factors associated with rural closure were for-profit ownership and community hospital status, lack of accreditation by the Joint Commission on Hospital Accreditation, a greater number of other hospitals in the county, fewer and narrower scopes of services, and presence of a nursing or other long-term care facility (Note 3 ). The latter variable may simply have indicated that in a dynamic situation, the hospital had actually converted to a full-time, longterm care facility. In a companion study, in addition to the variables just mentioned, membership in a multihospital system was negatively associated with rural community hospital closure (Mullner, Rydman, Whiteis, \& Rich, 1989). This study scrutinized a much larger number of variables, including morbidity and mortality statistics, population density, and other demographic characteristics, as well as the number of other health service facilities in the county, and found no differences between closed rural hospitals and a control group of rural hospitals still in operation.

In a completely different approach, the General Accounting Office (GAO) examined rural hospitals that had dropped out of the Medicare program, an event that occurs when a hospital is closed or changes ownership (Zimmerman, 1988b)—changes in ownership, however, were excluded from the analysis. Using the Medicare/Medicaid Automated Certification System (MMACS) files, the author determined that 41 hospitals terminated their participation in Medicare from the inception of PPS (Oct. $1,1983)$ through the end of the study period, Dec. 12,1986. The three-year period before PPS (Oct. 1, 1980 through Sept. 30, 1983) witnessed 25 terminating hospitals. The absence of any other hospital in the county in which a hospital closed was used as a crude measure of diminished access. In the pre-PPS period only three terminated hospitals were located in such counties, whereas in the post-PPS period 14 such hospitals were found.

These figures are inconsistent with those of another recent analysis of rural hospital closure (Mullner, Rydman, \& Whiteis, 1990). Again using case-controlled techniques, the authors demonstrated that the incidence of rural hospital closure before PPS differed significantly from that after PPS implementation: 44 closures occurred during the three years before PPS; 117 
in the three years after PPS. The presence of certain services, e.g., respiratory therapy, physical therapy, CT scanners, were negatively correlated with closure. Interestingly, the presence of a hospital auxiliary was also a factor associated with hospitals remaining open, a factor that may be an indicator of the integration of the hospital into the community. As in earlier studies, the presence of a long-term care unit was associated with hospital closure.

By 1989 , the issue of rural hospital closure, as noted earlier, had become a focus of policy debate. The U.S. Congressional Research Service determined that 44 of 80 hospital closures in 1988 were rural facilities and that the total count from 1981 through 1988 was 190 rural hospitals out of 397 hospital closures nationally (47.9\%) (Merlis, 1989). On closer examination, seven of the hospitals that the AHA had determined were closed in 1988 were actually open in 1989, one had been closed since 1986, and 15 more were still open, but not as acute-care facilities (Merlis, 1989). Generally, criticisms of closure figures include their lack of accounting for facilities that have not actually closed but have converted to nonacute care facilities, that have consolidated or merged with another facility, or that have simply changed their names as can happen with acquisition by or affiliation with a multihospital system. Finally, new hospital construction and replacement are not usually discussed in the closure research so that net figures are generally not available. A full accounting of these cases does not currently exist and remains an important item on the research agenda.

The growing national concern about the issue of rural hospital closures was evident in the request by a large number of U.S. Senators for the GAO to examine factors associated with rural hospital closure, as well as its effects on elderly and poor rural residents. In the first reports from this analysis (U.S. General Accounting Office, 1990a; 1990b), the GAO (1990b) concluded that 4 factors had a particularly large effect on hospital closures during the 1985 to 1988 period, including size fewer than 100 beds, occupancy rates of 40 percent or less, for-profit ownership, and location in either the northeastern or southern regions of the United States. After controlling for these and other differences in operating characteristics, rural hospitals did not face a greater risk of closure than urban institutions during this time period. This pattern led the authors to conclude that the vulnerability of rural hospitals appears due to their operating characteristics, rather than their location.

The review of rural hospital closures is important in a number of respects. First, it shows that hospital closure appears to have accelerated in the 1980s compared to the previous decade, but that urban hospitals for most of the decade have generally tended to close at a higher rate. Thus, operating and strategic environments have been stressful for both rural and urban hospitals. It is not clear, however, how likely this pattern is to continue: the most recent AHA data on 1989 closings indicate that, for the first time, twice as many rural hospitals closed as urban institutions (44 versus 21) (Friedman, 1990).

The second point stems from the first: as in the earlier discussion of rural- 
urban hospital performance comparisons, there is some question of the relevance of the contrast. As some of the research makes clear, major distinctions between closed and open rural hospitals exist and need further exploration. It may be that research needs to focus more on the effects of rural hospital closure on the communities and populations served. Issues of need, availability, access, and costs are critical to this examination.

Third, by trying to explain closure, this research suggests avenues for inquiry using other measures of rural hospital strategic activity. Closure is an extreme outcome or decision point on a continuum of strategic management possibilities. The fact that certain variables are correlated with closure may mean that they are also correlated with other strategies. Hence, these variables provide the basis for fruitful inquiry into their association with other strategic management activities. For example, do rural hospitals that have long-term care facilities less often join multihospital systems than those without such services? Do rural hospitals that are accredited by the Joint Commission on Accreditation of Healthcare Organizations more frequently engage in diversification and vertical integration schemes?

Fourth, the closure literature illustrates a fundamental problem with almost all the research on rural hospitals: the causal connection between factors correlated with closure is unclear. The best example of this is the positive correlation between long-term care facilities and closure. Does a rural hospital close because its long-term care unit is draining away scarce operating and capital resources, or is closure the logical outcome of evaluating that the strength of a long-term care facility overrides the weakness of the acute-care unit? Most studies assert that closure is the outcome of various factors; but, most study designs, except the Longo and Chase (1984) report which used lagged explanatory variables, inhibit untangling the causal processes. This problem exists because most designs do not permit modeling for simultaneous or reciprocal causation, do not take into account lagged explanatory variables, do not explicitly use time as a variable, or all of these. These problems are more than academic: adding or expanding services like CT scanners, or physical and occupational therapy, may be interpreted as causing improved rural hospital performance. On the other hand, it may be that the more financially viable rural hospitals are the institutions that add and expand such services and whose success is related to some other more basic feature. These are precisely some of the most important research issues facing rural hospitals, and there are no clear answers concerning either the correlates of such service acquisition or the causal direction of the variables. The strengths and weaknesses of the closure literature, however, help illuminate the research path ahead.

The fifth and final point relates to the lack of systematic examination into the outcomes of closure, although many have called for such research (cf. Damasauskas, 1988). There is no lack of anecdotal, even riveting, case reports of the results for specific communities of a hospital closure (cf. Bean, 1988). However, large sample or longitudinal studies directly examining the outcomes of closures do not yet exist. One recent study that attempted 
to address these issues was prepared for the Prospective Payment Assessment Commission (ProPAC). It examined declining admission rates for five states, comparing rural and urban levels. Although rural area admission rates per 1,000 Medicare beneficiaries, adjusted for age and sex, declined by 22 percent between 1984 and 1986, the levels in each of the two years were higher than the comparable urban levels (Codman Research Group, Inc., 1990). Hospital closure was not addressed as either a cause or a consequence of the declining rates. But, because the closure literature shows that closures were roughly at equal rates for rural and urban areas during this time (Mullner \& Whiteis, 1988), we may assume that closures contributed equally, to the extent that they contributed at all, to the decline in admissions.

Because the declining rural rates were equal to the urban rates, especially for elective surgery and technologically intensive care, the ProPAC-commissioned report concluded that "...access to inpatient services for rural Medicare recipients is not impaired despite decline in use of rural hospitals and the closure of some" (Codman Research Group, Inc., 1990, p.22). But, the conclusion is weakened by the study's equating hospital admissions, a utilization measure, with access, a broader concept related to barriers to care (Donabedian, 1973). As a study of the consequences of rural hospital closure, its conclusions are difficult to interpret.

In view of the lack of research on the effects of hospital closure, Doeksen, Loewen, and Strawn (1990) simulated the effect of such a closure on an Oklahoma community. The simulation suggested that in a community of 2,600 people, the closure of its 45-bed hospital, employing 43-FTE employees, would cause 51 people to be unemployed in the year of the closing with community income $\$ 659,800$ lower than it would have been if the hospital had remained in operation. These estimates are consistent with earlier research (Christianson \& Faulkner, 1981) suggesting that average annual salaries generated by a rural hospital approximated $\$ 600,000$, and that total community income directly and indirectly stimulated by the hospital was between $\$ 700,000$ and $\$ 1$ million. Christianson and Faulker (1981) concluded that closure would produce the economic demise of the town in question.

In summary, we know a good deal descriptively about rural hospital closure and have some economic impact estimates. The underlying research design problems and the lack of large-sample studies mean, however, that we still have much to learn about the causes and consequences, particularly on health care delivery and the population's health, of this dramatic form of strategic management activity.

\section{Diversification and Vertical Integration}

Diversification and vertical integration were two closely allied and favored strategies of the 1980s. Although there is debate about how each 
differs (Clement, 1988; Mick \& Conrad, 1988), the important point is that both strategies involve the addition of services-either health care- or nonhealth care-related - to the rural hospital. Some, such as Reid and Smith (1984) who drew on experience in New Mexico, argued that for many sparsely settled rural areas, rural systems integrating primary, secondary, and tertiary services under one umbrella were badly needed.

One problem in addressing this issue is the lack of comprehensive studies describing just exactly what rural hospitals have or have not done during the 1980s. Aggregate data, derived from AHA sources, indicate that between 1982 and 1985, the following changes were registered by rural hospitals: organized outpatient departments increased from 657 to 973; psychiatric outpatient services, from 121 to 144; rehabilitation outpatient services, 428 to 527; alcohol and chemical dependency outpatient services, 164 to 212 ; home health care, 256 to 678 ; and health promotion programs, 605 to 914 (Robinson, 1987). Ultrasound units grew from 1,470 units to 1,$921 ; \mathrm{CT}$ scanners from 243 to 864 . The growth of outpatient surgery was steady as well: 1981 surgeries amounted to 559,$000 ; 1985$ surgical procedures totaled 1,189,000, a 47 percent increase (Robinson, 1987).

In a study of rural and urban hospitals, 155 rural hospitals-all members of one of eight multi-institutional systems-were assessed in comparison to the urban hospital members of these eight systems (Shortell, 1988a). Urban hospitals had an average of 10.1 out-of-hospital diversified services, whereas rural hospitals had 8.7 such services. A difference emerged, however, in services to the elderly (e.g., geriatric assessment/counseling/case management, geriatric daycare, freestanding skilled nursing facilities or intermediate care facilities) which were more likely to be offered by the rural hospitals. Otherwise, the prevalence of diversified activities was generally lower among rural hospitals in this sample (Shortell, 1988a).

What evidence is there that diversification of services has been an effective solution to rural hospital financial problems? Very few studies exist that address this question. A national survey of 753 responding hospitals out of a sample of 2,000 (37.7\% response rate) examined 18 diversification strategies. The authors concluded that freestanding outpatient surgery programs were the most profitable of all diversification strategies. All other service diversifications, except wellness and health promotion, also made money (Sabatino \& Grayson, 1988). Unfortunately, the data were not examined for rural versus urban differences, but they were disaggregated by large regional groups. If one uses the "Upper Midwest" (the Dakotas, Nebraska, Kansas, Minnesota, Iowa, and Missouri) and the "Southwest" (Oklahoma, Texas, Arkansas, and Louisiana) as crude proxies for rural hospital locations, one finds that in the Upper Midwest, the most profitable services included freestanding outpatient diagnostic services, retirement community housing, and freestanding outpatient surgical services. Services predominantly losing money or breaking even included sports medicine clinics, wellness and health promotion clinics, women's medicine, HMOs, and emergency and trauma satellite clinics. In the South- 
west, freestanding outpatient surgery once again most frequently showed a profit followed by cardiac rehabilitation, and substance abuse services. Services losing money were retirement community housing, HMOs, and wellness and health promotion clinics.

A California-based study, using 1978 to 1983 data, but unfortunately also not separating rural from urban hospitals, concluded that diversification did not increase profits (Clement, 1987). The one variable in the analysis that might be a proxy for rural-urban location, county per capita income, showed statistically nonsignificant partial regression coefficients in the several models tested. In other words, hospital location in a low per capita income county produced no effect on financial measures, net of all other factors. It is possible that diversification offers neither increased profitability nor reduced financial risk for rural hospitals in California.

These indirect, but provocative, data suggest much needed research on the rural hospital experience. First, there appears to be great variation among the different diversification and vertical integration strategies pursued. Second, there is no indication of what the covariates of diversification and vertical integration are: some obvious candidates would be bed size, ownership, and regional location, but the research still needs to be done. Third, sound evidence supporting (or rejecting) the claim that financial improvements follow diversification and vertical integration strategies does not currently exist. Furthermore, there is empirical evidence from other industries that, under conditions of environmental stress, a sounder strategic management option would be divesting and downsizing of core business units to ensure financial viability (cf. Harrigan, 1985). Rural hospitals may suffer from handicaps that hamper capitalizing on diversification and vertical integration: e.g., lack of knowledge of alternative strategies; absence of capital sources; weak managerial skills; scant opportunity or patient/client population; and possible restrictions on managerial discretion imposed by state, county, or local governments.

\section{Swing Beds}

If swing beds are considered a strategic management diversification and vertical integration strategy, then research results appear to be more positive (Shaughnessy \& Schlenker, 1986). Before Medicare implemented its swing-bed program, the only option open to rural hospitals to providelongterm care services was to open a part of its hospital as a distinct unit. The problems with this approach were well known: no acute-care patients could use those beds, separate staff were needed for the long-term care section, and Medicare reimbursement required that the long-term care unit be considered a separate cost center, forcing much higher hospital overhead costs onto the unit than if it had been a separate, freestanding unit (Henderson \& Moomaw, 1986). Medicare implementation of the swing-bed pro- 
gram changed this situation so that the reimbursement methodology did not penalize the hospital for operating long-term care swing beds as part of the hospital. For some rural hospitals, criteria for eligibility prohibited their participation: the hospital had to have Medicare approval, 50 or fewer acute care beds (excluding ICU and newborn beds) (Note 4), 24-hour nursing coverage, and state-approved certificate of need for the provision of skilled nursing services.

Assessments of the swing-bed programs have been generally supportive (c.f., Spies, 1986). Richardson \& Kovner (1986) found that for 26 small rural hospitals in five states, declining levels of total patient days and acute-care patient days were offset by the increase in swing-bed admissions. A case study of a 34-bed Missouri hospital cited a $\$ 25,000$ contribution to the hospital's operating margin, exclusive of grant funds (Henderson \& Moomaw, 1986). A large-sample evaluation showed that about 40 percent (899) of eligible rural hospitals were certified to provide swing beds (Shaughnessy, Schlenker, \& Silverman, 1988). Further, the incremental costs of providing this care were less than the average per-diem swing-bed revenues.

\section{Sole Community Provider}

To some degree the decision by a rural hospital to obtain (or to refrain from seeking) sole community provider (SCP) status may be viewed as a strategic management activity. There may be financial benefits associated with this designation: exemption from the Tax Equalization and Fiscal Responsibility Act (TEFRA), limitations on reimbursable costs, reimbursement under PPS according to a system that gives heavier weight to hospitalspecific costs, and eligibility for special payments in the event of significant volume shortfalls. But participation is irregular. In 1985, Farley calculated that only 37.4 percent (137) of those hospitals that appeared to qualify for SCP status actually did apply (Farley, 1985). By 1987, there were 205 hospitals designated as sole community providers. Of these, 112 were actually not eligible to be SCPs according to then current HCFA guidelines. However, because of pre-PPS state-level and other special arrangements for these hospitals, they were permitted to be designated SCPs. Of 215 hospitals strictly eligible to be designated as SCPs, only 93 elected SCP status, while 122 hospitals did not (Guterman, personal communication, 1987).

In short, some rural hospitals managed to obtain designation when they were not officially eligible, whereas others that could have qualified did not bother because of a lack of awareness, indifference, or the belief that SCP status would actually be a detriment to the hospital. When Congress passed the 1989 Omnibus Budget Reconciliation Act, not only did it provide for a full equalization of Medicare payments to rural and urban hospitals by 1995 , but it also liberalized the definition of a SCP by lowering the distance 
the hospital was required to be from the next neighboring hospital from 50 to 35 miles. In addition, the legislation enables the secretary of Health and Human Services to classify rural hospitals with an even closer neighbor as SCPs if other criteria are met (National Rural Health Association, 1989). Hence, rural hospital managers and others associated with a given hospital, once they have determined whether they might qualify for SCP status, must decide whether to do so.

One study of SCP hospitals found that they tended to be small, not-forprofit, and located in the western half of the nation (Farley, 1985). After controlling for size and location, SCPs had less severe case mixes, treated fewer Medicare patients, had shorter lengths-of-stay, and operated with lower occupancy rates. They were more likely than their peers to have intensive care units. There was some suggestion that their financial status may have been worse. A recent GAO analysis using Fiscal Year 1987 data (U.S. General Accounting Office, 1990a) concluded that SCP status had been ineffective in protecting hospitals so designated from large Medicare losses. The GAO report also reasoned that improved payment made possible by the 1989 Omnibus Reconciliation Budget Act should alleviate large losses under Medicare and help protect these institutions. Further analyses of these issues must continue as an important part of the $1990 \mathrm{~s}$ research agenda.

\section{Horizontal Integration and Multihospital System Affiliation}

Many argue positively for the potential effects of horizontal integration-multihospital linkages-on rural hospital survival (cf. Grim, 1986). Among independent hospitals, these interhospital arrangements cover a spectrum of activities: formal affiliations in areas like joint residency programs or patient transfer and referrals; shared service agreements between two or more hospitals; and a variety of consortia such as voluntary health planning councils (DeVries, 1978). Another multi-institutional arrangement is the multihospital system, defined as two or more acute care hospitals that are owned, leased, sponsored or managed by a single corporate entity.

Rural hospital multihospital affiliations did increase in the early $1980 \mathrm{~s}$ when compared to earlier periods (Lewis \& Parent, 1986). Between 1970 and 1979,174 rural hospitals with fewer than 100 beds had joined some kind of system; in just the three-year period 1980 to 1983, 233 similarly sized rural hospitals joined systems. In 1983, 490 hospitals, almost one fourth of rural hospitals with fewer than 100 beds, were affiliated with multihospital systems; and, 37.8 percent of these were with for-profit systems. In 1988 there were 2,000 hospitals in 303 systems, and another 572 hospitals were contract-managed by systems. These data, however, were not tabulated 
separately for rural and urban hospitals (American Hospital Association, $1989 \mathrm{~b}$ ), and more up-to-date rural-urban figures have not been published.

Several studies have compared, with mixed results, the efficiency and cost performance of autonomous hospitals with those in a multi-institutional arrangement (c.f., Coyne, 1982; 1985). These studies, however, have not distinguished between rural and urban systems or freestanding hospitals. In virtually the only large-scale study of its kind, Berry and colleagues (Berry, Tucker, and Seavey, 1987; Seavey and Berry, 1986) used pre-PPS data from the AHA to examine the efficacy of multihospital system affiliation for distressed small rural hospitals. They found few differences in performance measures in comparisons among rural hospitals that were (1) independently owned and self-managed, (2) independently owned but managed by a system, and (3) both owned and managed by a system. They concluded that system linkage may not solve the problems of these hospitals. Research on the acquisition decisions of large systems by Morrisey and Alexander (1987) indicates that in the past these decisions have been fueled by the ability to find hospitals already in favorable economic environments. Their findings suggest that large national systems are unlikely to offer solutions for the majority of rural hospitals experiencing financial difficulties.

In fact, in a comprehensive analysis of studies to date, Shortell (1988b) reviewed a series of positive indicators allegedly associated with multihospital affiliation and found scant evidence that high performance had been achieved. Economies of scale did not seem to exist beyond bulk purchasing arrangements, higher levels of efficiency did not appear to be present, system hospitals did not seem to be more profitable than nonsystem hospitals and they did not have greater access to capital. For-profit systems did show higher levels of financial performance and used debt financing more often. System hospitals neither offered more services to their communities, after bed size adjustment, nor provided more charity care. Some of these findings contradicted earlier research (cf. Levitz and Brook, 1985) which found that system-affiliated hospitals were more profitable, and had better access to capital (but they also had higher costs per case, longer lengths of stay, and less productive plant and equipment use).

In sum, despite advocacy for system affiliation, there is surprisingly little evidence that such arrangements work for rural hospitals; indeed, some study results appear to suggest the opposite. Clearly additional research is needed, and this topic should be added to the 1990 s research agenda.

\section{Marketing and Patient Retention}

The use of marketing techniques to persuade rural community residents to use the services of the local hospital has received less research attention than some other strategic management activities. Yet, the migration of rural 
patients to urban and suburban hospitals has been a well-publicized phenomenon. For example, R.D. Stevens (1989) showed that, for births and surgical procedures, rural hospitals lost admissions to urban hospitals. Rural emergency department services, however, increased in use, probably reflecting increases among the unemployed and uninsured.

As part of a larger 1985 to 1988 study of six hospitals in the Pacific Northwest, Hart, Rosenblatt, and Amundson (1989) conducted a survey of residents within each hospital service area. The authors found that market shares (the percentage of reported hospitalizations that took place in the local hospital) varied from 39.9 percent to 52.9 percent. The population that used the local hospitals was less affluent, less likely to have health insurance, and more likely to have identified a local physician as a regular source of care. Furthermore, households made up exclusively of members 60 years of age and older, and those with travel time no more than 30 minutes to the hospital were also more likely to use the community hospital. The reasons given for out-of-community use included the perception that the needed service was unavailable in the local hospital, physician referral to an out-ofarea hospital, and the perception of lower quality of care.

This complex problem, interwined with physician retention and malpractice cost issues (cf. Ambulatory Care Professionals of the American Hospital Association, 1990), has prompted efforts to use marketing to attract patients to rural facilities and their providers (cf. Jensen \& Hietbrink, 1987). However, the systematic evaluation of marketing efforts is not currently available, and should be performed. The Hart, Rosenblatt, and Amundson (1989) study discussed previously showed that a focus on specific subgroups and the dissemination of information on available services and quality could be helpful for rural hospitals, and evaluation studies should be able to detect the effects of these efforts on rural hospital utilization.

\section{Future Research}

From our perspective, a research agenda for the 1990 s is clear. First, work must continue on developing definitions and typologies that are useful in identifying the great variety among rural hospitals. This is important not only because of the reasons we have already cited, but also because there is an increasing, not decreasing, variety of rural hospitals due not only to strategic management efforts already discussed but also to major public and private funding for experimentation. Some of these programs are stressing a movement toward specialized services or low-intensity, short-stay facilities sometimes called Medical Assistance Facilities (MAFs). The 1989 Omnibus Reconciliation Budget Act legislation allocated $\$ 10$ million for grants in up to seven states to establish Essential Access Community Hospitals (EACHs), or Rural Primary Care Hospitals (RPCHs) (Alpha 
Center, 1990). The idea is that such facilities would be first-line treatment and observation units and would transfer patients who needed more intensive or comprehensive services. Thus, we may have to broaden our definition of rural hospitals even more.

A 1990s research agenda should continue to build on the suggestions of Moscovice (1989), emphasizing the continuing need for studies explaining rural-urban cost differences and cost variability among different kinds of rural hospitals. There continues to be controversy and conflicting findings in this area, and the issue has become deeply divisive and emotional. The cost issue has another important dimension: based on the WAMI case studies already discussed, Amundson and Hughes (1989) estimated the amount of health care dollars expended in three local communities in which a rural hospital was located. They compared this to estimates of the cost of what was required to support local health care services and found that from 70 percent to 134 percent differences existed in the excess of dollars spent over dollars needed. Thus, if there were ways that rural hospitals and their associated health services could staunch the outflow of dollars, either through better retention of patients seeking out-of-area care, through health care financing innovations that would keep insurance dollars in the local area (e.g., self-funded risk pools), or through provider-delivery organizations schemes that would encourage local use (e.g., preferred provider arrangements), then much of the financial stress of many rural hospitals might be alleviated. This is a fruitful area for further inquiry.

Attention is also needed on the effects of rural hospital stress, closure, and conversion, not only on the population's access to health care, but also on community health indicators. In view of predictions about the negative outcomes likely to be associated with the decline in availability of rural hospital care, we are struck by the relative absence of work in this area.

Finally, we argue for more research on the correlates and consequences of strategic management activity. In a thoughtful assessment of knowledge about rural hospital strategic activity, Smith and Piland (1990) concluded that there is a "...paucity of strategy research applied to rural hospitals..." and "...much work remains to be done in order to reach a better understanding of how rural hospitals can cope with their complex environments" (p. 144).

In the 1980s, the balance between prescription and evaluation heavily favored the former. As the 1990s begin, we are witnesses to major funding of rural hospital experimentation and innovation. If the 1980 s were the incubator of new ideas for rural hospitals, the 1990s should be the time of evaluation and testing. Research in the 1980s tended to be descriptive; the research of the 1990s needs to be analytical and explanatory. Our view of the literature leads us to a cautious optimism about the survival of rural hospitals. Stevens' (1989) thesis is that American hospitals, including rural hospitals, have been resilient and adaptable over the long term. Ermann's (1990) essay underscores the continuing support of public and private 
sources for rural hospitals in their time of need. None of this means that rural hospitals have not and will not continue to do battle with antagonistic forces. But, many rural hospitals are attempting to find solutions, and we need more understanding of the efforts that contribute to success. We hope this review will make a positive contribution to this endeavor.

\section{NOTES}

1. Cleverley reports that the subscribing HFMA hospitals, especially the rural hospitals, tend to be those that have better financial performance records (Cleverley, personal communication, 1990). Therefore, the rural hospital data, and to some extent the urban hospital data, may tend to overstate actual aggregate financial performance of all hospitals in these categories. However, because the bias is thought to be consistent over time, the evaluation of trends for these hospitals is less likely to be affected by this reporting bias.

2. We thank Jack R. C. Wheeler for his advice regarding interpretation of the HFMA financial data.

3. The effect of the presence of a long-term care facility, however, could be confounded with hospital bed size. Two studies of smaller rural hospitals (less than 100 beds) showed that in 1983, 1985, and 1987, long-term care facilities were correlated with smaller bed size, lower occupancy levels, and lack of JCAH accreditation, factors generally associated with closure (Bowlyow, 1989a; 1989b).

4. In 1987, P.L.100-203 expanded eligibility to hospitals with fewer than 100 beds.

\section{REFERENCES}

Alpha Center. (1990). A description of the Essential Access Community Hospital (EACH) Program. Washington, DC: Author

Ambulatory Care Professionals of the American Hospital Association. (1990). Rural health care delivery and financing: Results of eight case studies. Outreach, 1(3), 1, 3.

American Hospital Association. (1985, June 10). Rural hospitals face upheaval. Media Background Sheet, No. 8.

American Hospital Association. (1987a). Environmental assessment for rural hospitals, 1988. Chicago, II: Author.

American Hospital Association. (1987b). Hospital statistics, 1987 edition. Chicago, IL: Author. American Hospital Association. (1988). Profile of small or rital hospitals, 1980-86. Chicago, IL: Author.

American Hospital Association. (1989a). Hospital statistics, 1989-90 edition. Chicago, IL: Author. American Hospital Association. (1989b). Guide to the healt care field. Chicago, IL: Author.

Amundson, B.A., and Hughes, R.D.(1989). Are dollars really the issue for the survival of rural health services? Rural Health Working Paper Series. 1(3). Seattle, WA: WAMI Rural Health Research Center, University of Washington.

Amundson, B.A., \& Rosenblatt, R.A. (1988). The rural hospital project: Conceptual background and current status. Journal of Rural Health, 4(2), 119-138.

Bailey, C.W., Boff, J.F., \& Rampmeier, W.A. (1988). Report on Medicare inequities. Unpublished manuscript.

Bean, E. (1988, January 4). In poor health: Small rural hospitals struggle for survival under Medicare setup. The Wall Street Journal. pp. 1,8.

Berry, D.E., Shelby, R.L., Seavey, J., \& Tucker, T. (1988). Frontier hospitals: Endangered species and public policy issue. Hospital and Health Services Administration. 33(4), 481-496.

Berry D., Tucker, T., \& Seavey, J. (1987). Efficacy of system management or ownership as 
options for distressed small rural hospitals. Journal of Rural Health, (2), 61-75.

Boeder, S. (1989, July 5). Rural health care: challenges for the 1990s. Hospitals, p. 66.

Boissoneau, R.(1985, December 16). Rural hospital CEOs: A new breed. Hospitals., pp. 79-81.

Bowen, O. (1987). Report to Congress: Studies of urban-rural and related geographical adjustments in the Medicare Prospective Payment System. Washington, DC: Department of Health and Human Services.

Bowlyow, J.E. (1989a). Long-term care in small rural hospitals. The Gerontologist., 29, 81-85.

Bowlyow, J.E. (1989b). Trends in small rural hospitals with long-term care beds, 1983-1987. Paper presented at the Annual Meeting of the American Public Health Association, Chicago, IL.

Buada, L., Pomeranz, W. \& Rosenberg, S. (1985). Laying the groundwork: Planning for change. Rural hospitals: Strategies for survival, (Monograph No. 1). Kansas City, MO: National Rural Health Association.

Christianson, J.B. (n.d.) Economic issues in the reduction of rural hospital capacity: A research summary, Report to the National Center for Health Services Research, Department of Health, Education and Welfare Grant No. If R03-H5-033745-01). Washington, DC: Department of Health, Education and Welfare.

Christianson, J.B., \& Faulkner, L. (1981). The contribution of rural hosptials to local economies. Inquiry., 18(1), 46-60.

Clark, J.D., Hamilton, R.A., \& Lester, J. (1989). The status of Michigan's smaller and rural hospitals. Lansing, MI: Michigan Hospital Association.

Clement, J.P. (1987). Does hospital diversification improve financial outcomes? Medical Caree, 25(10), 988-1001.

Clement, J.P. (1988). Vertical integration and diversification of acute care hospitals: Conceptual definitions. Hospital and Health Services Administrationn. 33(1), 99-110.

Cleverley, W.O. (1988). Hospital industry financial report, 1983-1987. Westchester, IL.: Healthcare Financial Management Association.

Cleverley, W.O. (1989a) Hospital industry financial report, 1984-1988. Westchester, IL: Healthcare Financial Management Association.

Cleverley, W.O. (1989b). Hospital industry performance report, 1984-1988. Westchester, IL: Healthcare Financial Management Association.

Codman Research Group, Inc. (1990). The relationship between declining use of rural hospitals and access to inpatient services for Medicare beneficiaries in rural areas., (Technical Report \#E-90-01). Washington, DC: Prospective Payment Assessment Commission.

Coffey, R.M., \& Farley, D.E.(1988). HCUP-2 Project Overview., (DHHSPub. No. [PHS] 88-3428). Rockville, MD: Department of Health and Human Services.

Cordes, S.M. (1989). The changing rural environment and the relationship between health services and rural development. Health Services Research, 23(6), 759-784.

Coyne, J.S. (1982). Hospital performance in multihospital systems: A comparative study of system and independent hospitals. Health Services Research. 17(4), 303-329.

Coyne, J.S. (1985). Assessing the financial characteristics of multi-institutional organizations. Health Services Research. , 19(6), 701-715.

Cromwell, J. (1989). An analysis of the prospective payment system's labor-nonlabor share by diagnosis-related group. Health Services Research, 24(2), 213-236.

Cromwell, J., Mitchell, J.B., Calore, K.A., \& Iezzoni, L. (1987). Sources of hospital cost variation by urban-rural location. Medical Care 25(9), 801-829.

Cromwell, J., \& Puskin, D. (1989). Hospital productivity and intensity trends: 1980-87. Inquiry, $26(3), 366-380$.

Damasauskas, R. (1988). Health care environment: Access, payment, and the rural hospital. In L. Straub, \& N. Walzer (Eds.), Financing rural health care, (pp. 43-63). New York, NY: Praeger.

Deloitte and Touche and Health Care Investment Analysts, Inc. (1989). The sourcebook: The comparative performance of U.S. hospitals. Chicago, IL: Deloitte and Touche.

DeSalvo, C.P.(1986, April 5). Rural hospitals study the market. Hospitals. p. 65.

DeVries, R. (1978, March). Strength in small numbers. Hospitals. pp. 81-84.

DeVries, R. (1988, September/October). When you've seen one, that's all you've seen. Healthcare Forum Journal, pp. 38-39.

Doeksen,G.A., Loewen, R.A., \& Strawn, D.A. (1990). A rural hospital's impact on a community's 
economic health. Journal of Rural Health., (1), 53-64.

Donabedian, A. (1973). Aspects of medical care administration: Specifying requirements for health care. Cambridge, MA: Harvard University Press.

Ermann, D.A. (1990). Rural health care: The future of the hospital Medical Care Review. 47(1), 33-73.

Ernst \& Young (1990). OBRA 1989: New reductions, regulations, and challenges. Unpublished manuscript.

Fackelmann, K.A. (1986, August 11). Rural hospitals in jeopardy? Medicine and Health Perspectives, pp. 1-4

Farley, D.E. (1985). Sole community hospitals: Are they different? A statistical analysis of the hospitals and their treatment under TEFRA and PPS, (DHHS Pub. No. [PHS] 85-3348). Rockville, MD: Department of Health and Human Services.

Finch, L.E., \& Christianson, J.B. (1981). Rural hospital costs: An analysis with policy implications. Public Health Reports, 96(5), 423-433.

Folger, J.C. (1990). Strategic plans provide lasting solutions to rural crisis. Healthcare Financial Management., 44(4), 25-30.

Friedman, E. (1990). Analysts differ over implications of more hospital closings than openings since 1987. Journal of the American Medical Association., 264(3), 310-314.

Gifford, B. D., \& Mullner, R. M. (1988). Modeling hospital closure relative to organizational theory: The applicability of ecology theory's environmental determinism and adaptation perspectives. Social Science and Medicine., 27(11), 1287-1294.

Grim, S.A. (1986, January/February). Win/win: Urban and rural hospitals network for survival. Hospital and Health Services Administration., pp. 34-46.

Guterman, S., \& Dobson, A. (1986). Impact of the Medicare prospective payment system for hospitals. Health Care Financing Review, 7(3), 97-114.

Harrigan, K.R. (1985). Strategic flexibility: A management guide for changing times. Lexington, MA: Lexington Books.

Hart, L.G., Rosenblatt, R.A., \& Amundson, B.A. (1989). Rural hospital utilization: Who stays and who goes? Rural Health Working Paper Series., 1(2). Seattle, WA: WAMI Rural Health Research Center, University of Washington.

Hart, L.G., Amundson, B.A, \& Rosenblatt (1990). Is there a role for the small rural hospital? Journal of Rural Health., 6(2), 101-118.

Henderson, D.R. \& Moomaw, A. (1986, November). Swing beds: An approach to hospital utilization. Healthcare Financial Management., pp. 46-50.

Hendricks, A., \& Cromwell, J. (1989). Are rural referral centers as costly as urban hospitals? Health Services Research., 24(3), 289-309.

Hogan, C. (1988). Urian and rural hospital costs: 1981-1985., (DHHS Pub. No. [PHS] 88-3419). Rockville, MD: Department of Health and Human Services.

Hospital Research and Educational Trust. (1989). 1988 annual report. Chicago, IL: Hospital Research and Educational Trust.

Jensen, J. , \& Hietbrink, R. (1987, June 19). Rural physicians expand services to keep their patients from flocking to cities for medical care. Modern Healthcare., pp. 44,46.

Kelly, J.V., \& O'Brien, J.J. (1983). Characteristics of financially distressed hospitals., (DHHS Pub. No. [PHS] 83-3352). Rockville, MD: Department of Health and Human Services.

Kennedy, L. \& Dumas, B.M. (1983). Hospital closures and survivals: An analysis of operating characteristics and regulatory mechanisms in three states. Health Services Research $18(4)$, 489-512

Levit $z$, G.S., \& Brooke, P.P., Jr. (1985). Independent versus system-affiliated hospitals: A comparative analysis of financial performance, cost, and productivity. Health Services Research, 20(3), 315-339.

Lewis, B.L., \& Parent, F.D. (1986). Acquisition of small rural hospitals by multihospital systems. Journal of Rural Health., 2(2), 55-65.

Long, M.J., Fisher, J.C., \& Dreachslin, J.L. (1988). A comparison of the resource intensity of inpatients in urban and rural nonteaching hospitals. International Journal of Health Services, $18(2), 323-333$

Longo, D.R., \& Chase, G.A. (1984). Structural determinants of hospital closure. Medical Care, 22(5), 388-402. 
Mayer,J.D., Kohlenberg, E.R.,Sieferman, G.E., \& Rosenblatt, R.A. (1987). Patterns of rural hospital closure in the United States. Social Science and Medicine, 24(4), 327-334.

Merlis, M. (1989). Rural hospitals. Washington, DC: Congressional Research Service.

Mick, S.S., \& Conrad,D.A. (1988). The decision to integrate vertically in health care organizations. Hospital and Health Services Administration., 33(3), 345-360.

Mick, S.S., Morlock, L.L., Salkever, D., de Lissovoy, G., Malitz, F., \& Jones, A. (1990). Strategic directions for rural hospitals: Case studies from the Michigan-Johns Hopkins Rural Hospital Project. Paper presented at the Annual Meeting of the National Rural Health Association, New Orleans, LA

Morrisey, M. \& Alexander, J.A. (1987). Hospital participation in multihospital systems. In Scheffler, R., \& Rossiter, L. (Eds.), Mergers in health care: The performance of multi-institutional systems: Advances in health economics and health services research. Greenwich, CT: JAI Press.

Moscovice, I.S. (1989). Rural hospitals: A literature synthesis and health services research agenda. Health Services Research., 23(6), 891-930.

Moscovice, I.S., \& Rosenblatt, R. (1985a). A prognosis for the rural hospital: part I: What is the role of the rural hospital? Journal of Rural Health, 1(1),29-40.

Moscovice, I.S., \& Rosenblatt, R. (1985b). A prognosis for the rural hospital: part II: Are rural hospitals economically viable? Journal of Rural Health. 1(2),11-33.

Mullner, R., Byre, C.S., \& Kubal, J.D. (1983). Hospital closure in the United States, 1976-1980: A descriptive overview. Health Services Research, 18(3), 438-450.

Mullner, R.M., \& McNeil, D. (1986). Rural and urban hospital closures: A comparison. Health Affairs., 5(3), 131-141.

Mullner, R.M., Rydman, R.J., Whiteis, D.G., \& Rich, R.F. (1989). Rural community hospitals and factors correlated with their risk of closing. Public Health Reports, 104(4), 315-325.

Mullner, R.M., Rydman, R.J., \& Whiteis, D.G. (1990). Rural hospital survival: An analysis of facilities and services correlated with risk of closure. Hospital and Health Services Administration, 35(1), 121-137.

Mullner, R.M., \& Whiteis, D.G. (1988). Rural community hospital closure and health policy. Health Policy, 10, 123-135.

McCormick, B.(1986, February 20). Health promotion programs find their way into America's heartland. Hospitals, pp. 106-107.

National Rural Health Association. (1988). NRHA board votes to challenge HCFA's Medicare. Rural Health Care. 10(4), 1-2.

National Rural Health Association. (1989). Reconciliation bill for 1989 includes rural provisions. Rural Health Update, 3(12), 1.

Newald, J. (1986, March 20). Iowa's swing beds bring big bucks. Hospitals., pp. 105.

Oklahoma Medical Research Foundation. (1989). Fiscal health of Oklahoma hospitals: Financial margins. Tulsa, OK: Author, Center for Health Policy Research.

Reid, R.A., \&Smith, H.L. (1984). Integrated rural health care systems: Managerial implications for design and implementation. Journal of Ambulatory Care Management, (2), 13-28.

Richardson, H., \& Kovner, A.R. (1986). Implementing swing-bed services in small rural hospitals. Journal of Rural Health, 2(1), 46-60.

Robinson, M. (1987, December 5). Rural providers ask: What's a hospital? Hospitals, pp. 48-52.

Sabatino, F.G., \& Grayson, M.A. (1988). Diversification: More black ink than red ink. Hospitals. January $5,36-42$.

Seavey, J.W., \& Berry, D.E. (1986). Environmental responses in small rural hospitals. Journal of Rural Health, 2(2), 67-80.

Shaughnessy, P.W., \& Schlenker, R.E. (1986). Hospital swing-bed care in the United States. Health Services Research, 21(4), 477-498.

Shaughnessy, P.W., Schlenker, R.E., \& Silverman, H.A. (1988). Evaluation of the national swing-bed program in rural hospitals. Health Care Financing Review, 10, 87-94.

Shortell, S.M. (1988a). The characteristics and performance of rural hospitals: Findings from the multi-hospital systems study. New Alliances for Rural America. Washington, DC: National Governors' Association.

Shortell, S.M. (1988b). The evolution of hospital systems: Unfulfilled promises and selffulfilling prophesies. Medical Care Review, 45(2), 177-214.

Shortell, S.M., \& Zajac, E.J. (1990). Health care organizations and the development of the 
strategic-management perspective. In S.S. Mick and Associates (Eds.), Innovation in health care delivery: Insights for organization theory, (pp.144-180) San Francisco: Jossey-Bass.

Smith, H.L., \& Piland, N.F. (1990). Strategic adaptations to PPS by rural hospitals: Implications for theory and research. Journal of Rural Health, 6(2), 140-160.

Spies, A. (1986). Medicare swing-bed program helps Iowa hospitals. Small or Rural Hospital Report. 10(1), Chicago, IL: American Hospital Publishing, Inc.

Staw, B.M., Sandelands, L.E., \& Dutton, J.E. (1981). Threat-rigidity effects in organizational behavior: A multilevel analysis. Administrative Science Quarterly, 26, 501-524.

Stevens, R. (1989). In sickness and in wealth: American hospitals in the twentieth century. New York, NY: Basic Books, Inc., Publishers.

Stevens, R.D. (1989). Shifts in hospital services to urban areas in the north central states: An equity issue for rural people? Paper presented at the Annual Meeting of the American Public Health Association, Chicago, IL.

Sutton, R.I., \& D'Aunno, T. (1989). Decreasing organizational size: Untangling the effects of money and people. Academy of Management Review, 14(2), 194-212.

U.S. General Accounting Office. (1990a). Rural hospitals: Federal leadership and targeted programs needed. (GAO Pub. No. GAO/HRD-90-67). Washington, DC: Author.

U.S. General Accouting Office. (1990b). Rural hospitals: Factors that affect risk of closure. (GAO Pub. No. GAO/HRD-90-134). Washington, DC: U.S. General Accounting Office.

University of Minnesota Center for Health Services Research. (1990). The development and characteristics of rural hospital consortia. Findings., 9(1), 1-3.

Weiss, S.L., D.F. Phillips, \& Schuman, J.G. (1986). Managenent issues for rural hospitals. Chicago, LL: American Hospital Publishing, Inc.

Wilson, D.A., \& Hungerford, M.L. (1984). The state of rural Kansas hospitals: A study of hospitals in the first congressional district of Kansas. Unpublished manuscript.

Zimmerman, M. (1988a). Medicare: Share of hospitals' inpatient use and revenue. (GAO Pub. No. GAO/HRD-88-44BR). Washington, DC: Government Printing Office.

Zimmerman, M. (1988b). Medicare: Number of hospitals terminating participation since the program began. (GAO Pub. No. GAO/HRD-88-4). Washington, DC: Government Printing Office. 